\title{
Information interaction in socio-cultural information and educational environment of the University
}

\author{
Evgeny Noskov, Elena Lopanova*, and Natalia Savina \\ Private Educational Organization Institution of Higher Education "Omsk Humanitarian Academy", 4 \\ Chelyuskintsev, 2-a, 644105 Omsk, Russia
}

\begin{abstract}
The article presents an analysis of approaches to the definition of the concepts of "information interaction", "interactive information cooperation" in socio-cultural information and educational environment, understood as a set of conditions that contribute to the emergence and development of information educational interaction between subjects of educational process and means of ICT, functioning of organizational structures of pedagogical influence for the development of content, the development of cognitive activity of a student. The article describes the features of the process of information interaction in socio-cultural information and educational environment in the preparation of students; interaction in this case includes an interactive information resource using interactive means of information and communication technologies. The structure of socio-cultural information and educational environment as a form of interrelated information interaction between the subjects of educational process with an interactive information resource is proposed. Information interaction is carried out by the subjects of the educational process (the student, the teacher, the means of education functioning on the basis of information and communication technologies) and is provided by psychological and pedagogical influence.
\end{abstract}

\section{Introduction}

In current conditions, it is impossible to teach students outside of socio-cultural information and educational environment, the conditions of which allow to reveal, develop and realize the intellectual potential of the student in accordance with the individual goals of education. Consider the essence of information interaction as a key concept of the information and educational environment and the factor of teaching students at the University.

Analyzing the concept of "interaction" in the context of educational process, one can conclude that it is close in content to the concept of "communication": this is the exchange of information between people or objects. V. A. Krasilnikova interprets the primary process of purposeful practical actions of participants coordination in the electronic learning

\footnotetext{
* Corresponding author: evlopanova@gmail.com
} 
environment as pedagogical communication, the peculiarity of which is its implementation through computer telecommunications [1].

As information interaction (after I. V. Robert, T. A. Lavina, M. V. Lapenok, L. P. Martirosyan, L. I. Mironova, O. V. Nass, etc.) we will understand "...interaction between users based on the implementation of transmitting and receiving information process presented in any form (symbols, graphics, animation, audio, video information) in the implementation of feedback, developed means of conducting a dialogue while providing the possibility of collecting, processing, and transmitting information" [2, p.142]. The structure of information interaction as a unity of stable relationships between its elements is an internal form of its organization. The subjects of educational process in the information interaction are the teacher and the student; in addition, information interaction also includes a means of teaching based on information and communication technologies, providing psychological and pedagogical assistance in mastering the system of knowledge of a certain subject area, a set of skills and abilities to carry out educational activities to study the laws of the subject area, the development of the creative potential of a student [2, p. 143]

The aim of the article is to study the features of information interaction process in sociocultural information and educational environment of the University, to present the structure of socio-cultural information and educational environment as a form of interrelated information interaction of the subjects of educational process with an interactive information resource.

\section{Materials and methods}

Consider the essence of information interaction as a factor of student training.

Analyzing the concept of "interaction" in the context of educational process, one can conclude that it is close in content to the concept of "communication": this is the exchange of information, messages between people, various objects. In the researches [3-9, 12, 13], the factors that determine the functioning of the information and educational environment of an educational organization are identified, among which an important place is occupied by the implementation of information interaction between users and with screen representations of the objects under research; the ability to influence the processes or phenomena under consideration, educational subjects that take place and develop on the basis of an information educational resource; the ability to work in the context of the embedded learning technologies implementation focused on teaching the laws of a particular subject area.

Individual interaction in modern conditions, as a rule, is carried out through e-mail; information interaction of the subjects of educational process in more advanced versions is implemented through Zoom, Mirapolis, BigBlueButton, etc. Educational material is placed on the website in electronic form, which can be mastered by students without additional explanations. Collective talking, discussions, virtual electronic seminars, conferences, project execution, and other types of work that require prompt communication can be implemented through chats, Web conferences, and forums.

Active implementation of various forms of mediated information interaction in the information and educational environment allows one to get and develop the skills of pedagogically appropriate information interaction, especially important for the staff of educational organizations, which can include teachers, technical staff, administrators, web designers; an important role goes to the Internet provider [2, 4, 6 - 10]. Intensive interaction in the information and educational environment with the use of remote educational technologies requires the choice of an effective communication method of educational process subjects, which can be provided by the development of distance courses and methodological approaches to the implementation of pedagogically appropriate 
communication. The use of new combinations of teaching methods based on communication in small groups provides an increase in the methodological activity of teachers; the learning and teaching processes are activated through interactive forms of interaction (problem-based, cooperative, project-based learning; collaborative learning).

Under the influence of information and communication technologies, the ways of interaction in educational process are changing: in addition to traditional individual methods such as consultations, individual tasks, and the protection of completed tasks, collective and group methods of communication, such as online seminars, forums, and projects, are becoming more popular $[4,7,9,10,13,14]$. At the same time, there is a shift of roles in educational process: from the direct impact of teacher-student to the interaction of student-student, student - interactive educational resource (I.V. Robert [2, 6, 7], L.P. Martirosyan [3], V.A. Krasilnikova [1]).

Information interaction in information and educational environment, which is implemented in educational organizations on the basis of modern Web platforms, is characterized by certain specifics (availability of tools and services that ensure the reliability of communication in the conditions of a network Internet forum, chat, and video conference, individual communication, group communication in networks. At the same time, the interaction of the student with the teacher and the interactive educational resource takes place in a comfortably organized information environment, settings made for a specific user, saving the results of interaction and training, and the possibility of continuing activities in the next communication session.

In any educational organization, the information educational environment is organized on the basis of the software of a certain platform, which is intended for distance learning. In these conditions, it is provided: possibility of remote interaction, exchange of information with the teacher, other students; organization of cooperation in cognitive activities; conditions for the manifestation of creativity are created. At the same time, students, teachers, consultants and curators of training groups have access to information resources from any computer that has access to the Internet. To do this, students only need to have the skills to work on the Internet and with the system's services at the user level. However, teachers and curators of groups, in order to ensure such work, need to master the knowledge and skills for organizing the student's work in the information environment in accordance with the set pedagogical tasks [2, 4, 9, 13]. Based on the works of I.V. Robert on information and educational interaction [2, 5, 6] and V.A. Krasilnikova [1], one will highlight the features of information interaction process in socio-cultural information and educational environment when teaching students:

- mediation of information and educational interaction in the conditions of use by educational process subjects of various WEB platforms and means of communication (Moodle, Zoom, Mirapolis, etc.);

- efficiency of information and educational interaction between students, teachers and other interested participants (social workers, organizers of cultural events, responsible for working with teenagers and other specialists dealing with national security issues) when using the necessary information and information through network technologies in on-line and off-line modes of operation;

- individualization of information interaction, provided by the freedom of communication or training choice, the interlocutor- the subject of educational process or other interested participant;

- corporatism of information and educational interaction in collective or group communication, both when communicating between the subjects of educational process, and with other interested participants in communication, due to the possibility of choosing a group of interests; 
- mass nature of information interaction, due to the possibility of connecting an unlimited number of communication subjects (interlocutors);

- distribution and independence from the time and location of the information interaction subjects, both when communicating between the subjects of educational process, and with other participants interested in communication;

- multi-aspect information and educational interaction, allowing to organize the discussion of problems in the field of national security, ensuring the implementation of cross-subject relations, the presentation of information and interlocutors from other fields of knowledge;

- interculturality of information and educational interaction as an opportunity to communicate with representatives of another language environment and culture.

Acting as a component of socio-cultural information and educational environment, the potential of a distributed information resource creates conditions for the implementation of information activities of a group, collective or individual learner, while:

- we form a distributed information resource for educational purposes from selected and verified information sources;

- information and educational environment becomes a source of information of the semantic and technical-technological components of the discipline content, providing opportunities for working with it;

- we provide information activities with interactive sources of information between students and the teacher;

- integrative nature of information interaction is carried out in the conditions of open education through the use of the information potential of the information and educational environment.

\section{Results}

To implement the theoretical provisions developed by us, the Omsk Humanitarian Academy has created a software and methodological complex integrated with applied software products, databases, innovative methodological materials that provide active information interaction between the teacher and the student, students among themselves and an interactive distributed information resource for educational purposes [11]. The structure of the multimedia educational and methodological complex meets the requirements of the federal state educational standard. In the selection of ICT tools by the teacher, preference is given to active use of multimedia. In addition to pedagogical development of each topic, technological development of the content and structure of the didactic material based on multimedia information technologies is necessarily carried out. Development of the topic reflects the nature of access to the components of effective learning, the multimedia applications used, and navigation through them. Effectiveness of the training is ensured by the well-thought-out complex effect of the theoretical, reference, illustrative, training and control components of the specific topic of the lesson, the use of various channels of educational material perception, dosed assistance, depending on the level of student's readiness.

Content and instrumental composition of blocks for a particular topic depends on place of the discipline in the curriculum, its content, possibilities of placement in a multimedia environment, and interdisciplinary connections. A characteristic feature was the rejection of a selective approach to the selection of experimental subjects, the creation of a multimedia software and methodological complex is carried out for each topic of the discipline in accordance with the curriculum.

In these conditions, lectures are provided with modern multimedia tools, for example, cloud presentations created using Prezi.com service and different style of information 
presentation. In addition, the technology of static and dynamic video series, video conferences, webinars, and educational films is widely used. Presentation videos combine all types of visibility, and the Macromedia Director (Adobe Director) technology is used as a tool. This allows one to provide the presentation of the material in a variety of formats, to increase the learning effect of the lecture.

Seminar and laboratory classes include multimedia resource formats such as video cases, discussion films, training virtual simulators, training films, and web quests. This allows one to increase the level of the practical stage of training informatization. Multimedia tools are widely used to control the results of all-learning: in the off-line mode, tests for current control, final tests on the topic, and tests for intermediate control are performed in the multimedia class. Control tool is also the implementation of students' projects based on the use of multimedia tools.

\section{Conclusions}

In such a way, the analysis of approaches to the definition of the concepts of "information interaction", "interactive information cooperation" in socio-cultural information and educational environment, considered as a set of conditions that contribute to the emergence and development of information educational interaction between the subjects of educational process and means of ICT, allowed us to identify the features of the process of information interaction in teaching students. Goal setting and activities with the use of technical means as components of interactive information cooperation indicate the educational purpose of communication in the conditions of using hardware and software.

Automatic transfer of interaction skills from the traditional communication environment to communication mediated by information and communication technologies is not possible. Under the influence of socio-cultural information and educational environment, the communicative, perceptual, operational, and interactive aspects of students' and teachers' activities are undergoing serious changes. Psychological and pedagogical influence, which ensures the development of the student's creative potential, the formation of universal and general professional competencies, provides information interaction of educational process subjects.

Our researches on organization of the information and educational environment of a modern university based on the use of information and communication technologies continue. Currently, work is underway to clarify the specific model of software and methodological complex and to supplement the content for its further practical implementation. It should be noted that development of information and educational environment of organizations is one of the most promising areas for the development of informatization of education [12].

\section{References}

1. V.A. Krasilnikova, The use of information and communication technologies in education (OSU, 2012)

2. I.V. Robert, Theory and methodology of informatization of education (BINOM, 2014)

3. L.P. Martirosyan, Informatization of mathematical education: theoretical foundations (IIO RAO, 2012)

4. Z.K. Avdeeva, N.O. Omarova, Y.V. Taratuhina, Smart Education and Smart eLearning, 41, 219 (2015) 
5. I.V. Robert, Proceedings of the International Conference on the Development of Education in Russia and the CIS Member States (2018)

6. I.V. Robert, Materials of the International Scientific and Practical conference, 127 (2012)

7. I.V. Robert, I.S. Mukhametzyanov, A.A. Arinushkina, V.A. Kastornova, L.P. Martirosyan, ESPACIOS, 38(40), 32 (2017)

8. I.V. Robert, Development of the conceptual apparatus of pedagogy: digital information technologies Pedagogical informatics, 1, 108 (2019)

9. O.M. Karpenko, Scientific readings Actual problems of implementing e-learning and distance learning technologies, 2, 61 (SSU Publishing House, 2016)

10. I.Sh. Mukhametzyanov, Education management: theory and practice, 2(18), 70 (2015)

11. O.L. Osadchuk, E.V. Lopanova, N.V Savina, Journal of Physics (2020)

12. E.N. Dzyatkovskaya, A.A. Mamchenko, SHS Web of Conferences, 29, 1021 (2016)

13. E. Zvereva, T. Lavina, O. Fedorenko, O. Chupina, N. Topolskiy, The development of information educational environment, 4, 244 (2019)

14. I.M. Osmolovskaya, E.O. Ivanova, M.V. Klarin, V.V. Serikov, Y.B. Aliev, International conference "Education Environment for the Information Age - 2019", 598 (2019) 